\title{
KNOWLEDGE CITIES: EXAMINING THE DISCOURSE SMART VILLAGES, INTERNET CITIES OR CREATIVITY ENGINES
}

\author{
Ali A. Alraouf ${ }^{1}$ \\ Department of Architecture, Faculty of Engineering \\ UNIVERSITY OF BAHRAIN, KINGDOM OF BAHRAIN
}

\begin{abstract}
The world's growing cities are a critical fact of the $21^{\text {st }}$ Century, and represent one of the greatest challenges to the future. By the year 2050 cities with populations over three million will be more than double; from 70 today to over 150 . When knowledge is perhaps the most important factor in the future of city's economy, there is a growing interest in the concept of the "knowledge city". An acceptable definition of knowledge city might be it is not just a regular city. It is a growing space of exchange and optimism in which each and everyone can devote himself to personal and collective projects and aspirations in a climate of dynamism, harmony, and creativity. A world examination of the status of Knowledge Cities will reveal a tangible development in collective efforts of declaring and developing such cities around the globe. On the contrary, Arab cities are building technological isolated projects thinking that they are promoting the same concept. An examination of projects like Egypt' Smart Village and Dubai's Internet City and Knowledge Village will be helpful in evaluating the knowledge status of contemporary Arab Cities.
\end{abstract}

The purpose of this paper is to explore the knowledge city concept in depth. It will discuss the principles of a knowledge city, and portrays its distinguishing characteristics and processes. I'll argue in this paper that the concept of 'Knowledge Cities' is rooted in the urban, cultural structure of traditional Arab cities. Therefore an attempt to foster this concept in today's Arab cities would not be possible by building isolated technological statement scattered around the city. Alternatively, the rise of the network society, global networks, linked cities and existence of smart communities should construct the basis for shaping Arab Knowledge Cities.

In addition, the paper will introduce the concept of Urban Creativity Engines, and examples of various types will be presented. I Il argue that this is a more comprehensive concept for constructing and evaluating knowledge cities. Although this concept and its terminology is new, the paper will prove that there are many historical examples, regionally and internationally, of knowledge cities and Innovation/Creativity

'Assoc. Professor Dr. Ali A. Alraouf can be contacted at alialraouf@yahoo.com 
Engines. A focus on the traditional built environment of the Middle Eastern cities will be included to examine the main hypothesis of the paper.

Keywords: Smart Communities, Knowledge Cities (KC), Network Society, Community Architecture, Global Networks, Creativity Engines

\section{INTRODUCTION}

'In the knowledge economy, human development depends not on having more but by being more-becoming a co-creator to the future of humanity'

Dr. Thomas F. Malone

When knowledge is perhaps the most important factor in the future of city $\mathrm{s}$ economy, there is a growing interest in the concept of the knowledge city. Hence, what are the qualities of future cities becomes a crucial question and its answer creates a challenge for architects, urban designers, planners, developers, and decision makers around the world.

Globally, there has been an explosion of worldwide initiatives to reconsider contemporary cities as hubs of knowledge and all its related activities. It seems that the challenge of human kind in the third millennium and in a postglobalized world is how to increase the innovation capacity and performance of cities by creating an active community of knowledge sensitive cities or regions which will rapidly learn from each other.

In addition, another explosion of cross-boundary internet activities took place. It creates a modern city management landscape that defies traditional geographical limits. It also creates a highway of networked knowledge operating in the best interest of our common good, but not on the expense of individual development.

\section{WHAT IS KNOWLEDGE CITY?}

$\mathrm{KCs}$ play fundamental roles in knowledge creation, economic growth and development. Edvinsson (2003) sees $\mathrm{KC}$ as a city that was purposefully designed to encourage the nurturing of knowledge. The notion of $\mathrm{KC}$ is interchangeable to a certain degree with similar evolving concepts such as 'knowledge-based clusters' (Arbonies and Moso 2002), 'ideopolis' (Garcia 2004) or 'technopolis' (Smilor et al. 1988a; Smilor et al. 1988b; Dvir and Pasher 2004). KC is also seen as an umbrella metaphor for geographical entities, which focus on knowledge creation and covers other knowledge zones 
such as 'knowledge corridors', 'knowledge harbours', 'knowledge villages' and 'knowledge regions' (Dvir 2003).

Ergazakis et al. (2004) refer a $\mathrm{KC}$ as a city that aims at a knowledge-based development, by encouraging the continuous creation, sharing, evaluation, renewal and update of knowledge. This can be achieved through the continuous interaction between its citizens and also between them and other cities' citizens. The citizens' knowledge-sharing culture as well as the city's appropriate design, ICT networks and infrastructures support these interactions.

This concept involves developing a path towards more viable, vibrant, and sustainable development. KCs have embarked on a strategic mission to firmly encourage the nurturing of innovation, science and creativity, within the context of an expanding knowledge-based economy and society. In this regard a $\mathrm{KC}$ can be seen as an integrated city, which physically and institutionally combines the functions of a science park with civic and residential functions. It offers one of the desirable paradigms for the sustainable cities of the future.

Knowledge cities are seen as fundamental to the economic growth and development of the $21^{\text {st }}$ century cities. Knowledge city is a new perspective of development which is based on knowledge, innovation and creativity. Leif Edvinsson (Dvir, 2004) defines Knowledge City as "a city that purposefully designed to encourage the nurturing of knowledge". Knowledge city is not just a city. It is a growing space of exchange and optimism in which each and everyone can devote himself to personal and collective projects and aspirations in a climate of dynamism, harmony, and creativity. What is unique about this definition is the focus on Knowledge city as a holistic environment for comprehensive development. Hence, it calls for different process of articulating the city structure and subsequently raises issues and concepts like transparency, democracy and sustainability.

\section{CITIES FOR A NEW MILLENIUM}

Advances in information and communication technologies (ICTs) are inevitably making societies and cities increasingly knowledge-based. The nature of city development changes accordingly as activities in the knowledge sector are becoming more important and they require conditions and environments which are different from commodity-based manufacturing activities (Knight 1995).

Globalization was made possible with the advent of the digital revolution and has turned the world into a global village; and, in this era of globalization, cities 
are regarded as arenas of accelerating change. Needless to say, cities themselves should likewise change dramatically. Saskia Sassen (2000) once referred to the four major interrelated functions that cities should perform in their attempt at becoming global. In his words, they should become "highly concentrated command points in the organization of the world economy; second, as key locations for finance and for specialized service firms, which have replaced manufacturing as the leading economic sectors; third, as sites of production including production of innovations, in these leading industries; and fourth, as markets for the products and innovations produced" (1991:3-4).

Castells (1996\&1998) has argued that a new type of society is rising in our contemporary cities due to the consequences of the information revolution. From a sociological point of view, Sassen (2000) has argued that cities in the information age should be perceived as nodes of an immense network of cultural, commercial and political transactions. Giving these points of view, it is obvious that the classical planning process and design guidelines of contemporary cities need a substantial revision. In a world which is best described as a global village with less and less boundaries, Knowledge and its physical representation in the built environment creates a major challenge and invite us to vision and predict the main aspects of the cities of a new millennium.

In this new collection of essays, Sassen (2002) and a distinguished group of contributors expand on the author's earlier work in a number of important ways, focusing on two key issues. First, they look at how information flows have bound global cities together in networks, creating a global city web whose constituent cities become "global" through the networks they participate in. Second, they investigate emerging global cities in the developing world-Sao Paulo, Shanghai, Hong Kong, Mexico City, Beirut, the Dubai-Iran corridor, and Buenos Aires. They show how these globalizing zones are not only replicating many features of the top tier of global cities, but are also generating new socioeconomic patterns as well.

In global cities, urban and regional planning has displayed a recent interest in designing policies to attract international investment and encourage economic growth in KCs. These policies also focused on creating social amenities and communities to attract knowledge workers (Martin 2001; Chen and Choi 2004). The key factors in attracting knowledge workers to $\mathrm{KCs}$ are mainly social relationships and quality of life of these cities (Mathur 1999; Leamer and Storper 2001; Robinson 2002; Santagata 2002). 


\section{EMERGING KNOWLEDGE CITIES AND INTERNATIONAL ATTEMPTS}

It is estimated that by 2030,60 percent of the world's population will be living in cities (Wagner 2001). As KCs creating skilled employment opportunities and economic growth, much of the urban development would occur around them. The major role of a $\mathrm{KC}$ is to provide its citizens with enabling conditions which foster knowledge creation, knowledge exchange and innovation.

There are already several cities that identify themselves as knowledge cities, or have strategic plans to become knowledge cities. These cutting edge cities are aiming to win competitive and cooperative advantage by pioneering a new environment and knowledge ecology for their citizens. The list includes some of these cities according to the Knowledge Cities Observatory (KCO) classifications:

- Melbourne, Australia_- its strategic plan for 2010 emphasize the path towards enhancing its position as a knowledge city.

- Delft, the Netherlands_- the city clustered its knowledge intensive projects included in the "delft knowledge city" initiative in 5 themes: soil \& water, information technology, innovative transport systems, environmental technologies.

- Barcelona, Spain - the activity of Barcelona Forum 2004, which manifests the cultural perspective which Barcelona adopted as a main theme for its knowledge sensitive development. Accordingly, the city was chosen to host the founding meeting of the distinctive Knowledge Cities Observatory (KCO).

- Palmerston North, New Zealand - this relatively small city puts education in the heart of its "knowledge city" manifest.

- Monterrey City, Mexico - the new governor set the goal of becoming a knowledge city among his top 5 priorities.

This short list shows how the concept of Knowledge Cities is spreading successfully to different geographic, cultural, social and economical contexts around the world.

The case of Melbourne deserves more analysis and attention. Melbourne's experience as a knowledge city needs to be further analysed. Melbourne's initiatives on science, technology and innovation and policies for economic and social development are setting an example for the holistic process of establishing $\mathrm{KCs}$ world wide. It also illustrates how the city administration 
played a key role in developing Melbourne as a globally recognised, entrepreneurial and competitive knowledge city.

\section{KNOWLEDGE CITIES/ZONES: REGIONAL ATTEMPTS}

The Middle Eastern cities are not only exceptions but would require major social transformations. These transformations in this paper would be regarded as preconditions towards the creation of knowledge cities. Furthermore, based upon what has been put forward in the introduction above, the rest of the paper would be devoted to spelling out the said preconditions or prerequisites. Considering so, sustainability and citizenship would be regarded as the most important strategies in the development of a knowledge-city project in the Middle East.

In an attempt to actualize the high-performance knowledge city, different initiatives took place in some of the Middle Eastern cities. Egypt, UEA, and Qatar are pioneers among other Arab countries in trying to inject knowledge entities in the structure of their major cities. Cairo and Dubai are witnessing a major development in this direction which results in a variety of projects where knowledge is a substantial component of their identity.

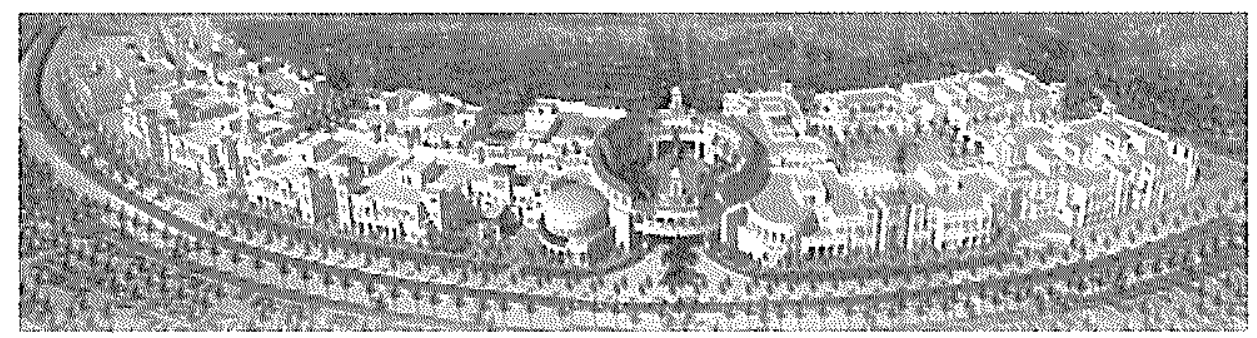

Figure 1: Dubai's recently opened Knowledge Village.

On the contrary of the comprehensive strategic planning of European and American knowledge cities, Arab cities are building technological yet isolated projects. This is considered as an attempt towards claiming a new identity for its contemporary cities as knowledge cities. An examination of projects like Egypt' Smart Village and Media City or Dubai's Internet City and newly launched project Knowledge Village will be helpful in evaluating the knowledge status of contemporary Arab Cities. Experiences and lessons learned from developed world Knowledge Cities initiatives must be used as a criterion for such an evaluation. 


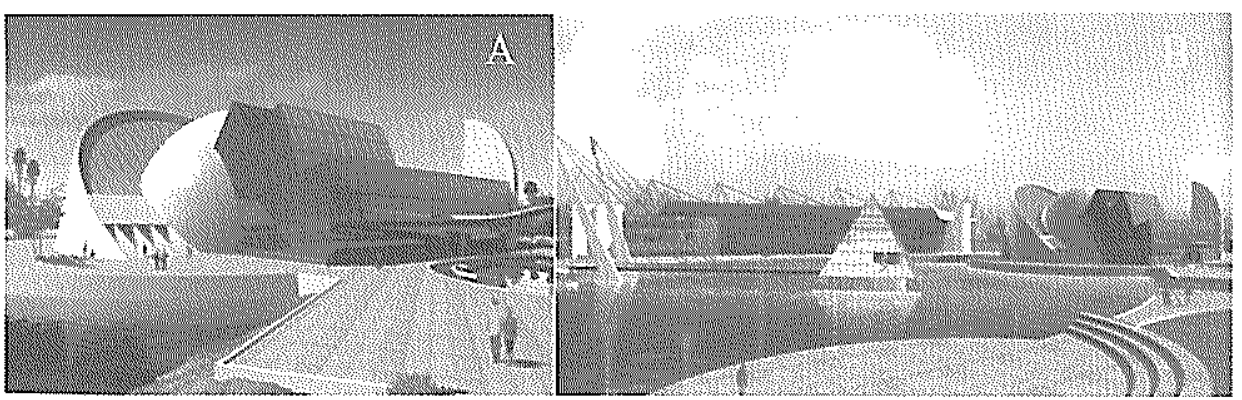

Figure 2: Smart Village project in Cairo - Egypt, is it really smart?

Another crucial point is that the concept of 'Knowledge Cities' is deeply rooted in the urban, cultural and even architectural structure of traditional Arab cities. Some traditional cities in Egypt, Iraq and Syria were designed as an arena for knowledge exchange. Therefore, an attempt to foster this concept in today's Arab cities would not be possible by building isolated technological statement scattered around the city. Alternatively, the rise of the network society, global networks, linked cities and existence of smart communities should construct the basis for shaping Arab Knowledge Cities.

\section{PRINCIPLES OF A KNOWLEDGE CITY}

The revolutionary transformation of knowledge has been made possible with the revolution in electronics which, in turn, has made the digital world a reality (see Sassen, 1991). This major innovation has led to as many transformations as possible in almost all aspects of life; cities, as arenas of accelerating change, not excluded. Hence, concepts such as digital city, dot com city, internet city, intelligent city, global city, and knowledge city are the by-products of these changes as mentioned above. In a narrow sense, Knowledge City would mean a city where the fruits of the IT Industry are applied to run it. In this regards, the management and control of city traffic was pioneer. However, in contrast to this narrow definition of Knowledge City, there is another view which claims that Knowledge City is not a novel phenomenon and "there are many historical examples of 'Knowledge Cities' and Innovation engines" (see Dvir, 2003:1).

The Kaieteur Institute for Knowledge Management and ENTOVATION International, Ltd. (http://www.entovation.com/), have published ten principles which govern the holistic formation of a knowledge city. These principles include the following: 
$\begin{array}{ll}- & \text { Knowledge Purpose } \\ \circ & \text { Knowledge commerce } \\ \circ & \text { Abundant Economy } \\ \circ & \text { Knowledge Fusion } \\ \circ \quad \text { Knowledge Governance }\end{array}$
- Knowledge Symmetry

- New growth Medium

- Knowledge-to-Democracy

- Boundary-less Intellectual Capital

- Knowledge Enabling Grid

For the purpose of this paper, I will try to shed some light on four of these principles which form a major importance and substantiate the argument of this paper.

\section{New growth Medium:}

Knowledge-Based Urban Development is the perfect new medium in which to grow more livable, stimulating, cleaner, intelligent, tolerant and meaningful communities' world wide.

\section{Knowledge Fusion:}

The Knowledge City is the culmination and synthesis and reintegration of the 'Creative City' and the 'Science City' where arts and sciences become unified in uniquely human twenty-first century urban ecology. To focus on one without the other would not be smart.

\section{Boundary-less Intellectual Capital:}

The knowledge city though it may be grounded in space and time, is ultimately unbounded by space and time, and this gives it greater potential global richness and reach.

\section{Knowledge Governance:}

In an era where there is growing unease, dissatisfaction and distrust in current governance regimes, the Knowledge City can facilitate new forms of Citizenship in which openness, transparency, accountability, and recall, replace fear, cynicism, fraud, and the knowledge gap expressed so often in "Who Knew'?

It is obvious that these elements are stressing the equal and fair distribution of knowledge within cities as oppose to creating gated and excluded centers for knowledge. The crucial point is the fact that knowledge cities are about engaging the whole community not limited and selected sectors of it. 


\section{CHARACTERISTICS OF A KNOWLEDGE CITY}

What makes a knowledge city perform optimally? The following list is compiled as a result of analyzing the published criteria by the Latin American Knowledge Development forum, Monterrey, Mexico (2003) and by the ENTOVATION 100, Barcelona, Spain (2004):

- A city that has instruments to make knowledge accessible to citizens.

- A network of public libraries that is compatible with the European standards.

- Access to the new communication technologies for all citizens.

- All cultural facilities and services with a central educational strategy.

- A city that has a newspaper- and book-reading level that is similar to the average European level.

- A city that has a network of schools connected with artistic instruction throughout its territory.

- A city that is respectful of the diversity of cultural practices of its citizens.

- A city that places the streets at the service of culture.

- A city that simplifies, through the provision of spaces and resources, the cultural activity of the community collectivises and associations.

- A city with civic centers that are open to diversity and that foster faceto-face relations.

- A city that makes available to citizens from other territories all the tools required for them to express themselves.

\section{TRADITIONAL ARAB/ ISLAMIC CITIES}

A close examination of the urban and architectural structure of a typical Islamic/Arab city reveals that many of the city's experience was based on exposing community members to knowledge either consciously or subconsciously.

Three main building types can be used in the context of this paper to illustrate the previous point. These buildings are: the Mosque, the School, and the Market. 


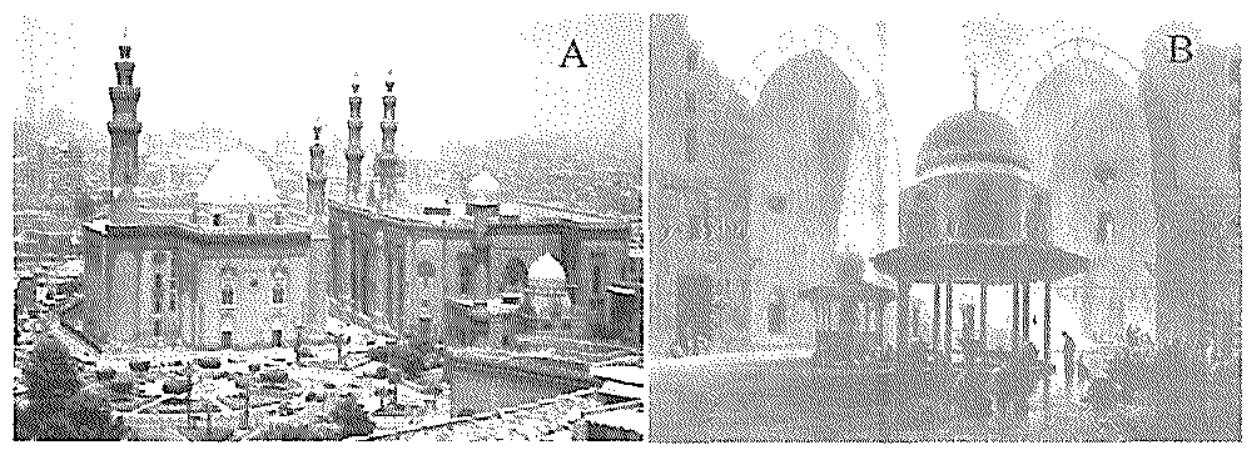

Figure 3: Madrasat Sultan Hassan, Cairo: Mosque as a knowledge centre.

The bazaar has always played an important role in the economy and social life of the city. In the broadest sense of the term, the bazaar is an organized system grouped into guilds. In an Iranian bazaar, the shops are usually grouped by profession; thus one alleyway may be occupied by carpet sellers, another by goldsmiths and yet another by coppersmiths. It acts as an interface between the town and the country, and has close links with the clergy.

\section{TOWARDS A MIDDLE EASTERN KNOWLEDGE CITY}

The question still remains, however, How to turn our cities into knowledge cities? To answer such a difficult question and in an attempt to draw a tangible conclusion to this paper, the concept of 'Urban Creativity Engine' will be introduced. Its reflection on city planning and design which can allow the emergence of Knowledge cities in the Middle East will be explored.

\section{Urban Creativity Engines}

Creativity is the process of turning knowledge and ideas into value. An 'Urban Creativity Engine' is a system that can trigger, generate, foster and catalyze creativity in the city. Typically it is a complex system that includes people, relationships, values, processes, tools and technological, physical and financial infrastructure. A close examination of the constructs of a typical city reveals that many of the city constructs can serve as Creativity Engines. However, not every University, or Library, or Industrial District, for example, do play the role of a true creativity engine. There is always a unique combination of intangible factors which turn a specific ordinary urban construct into an innovation engine. This set might include, for example, a strategic intention, an explicit vision to use it as a creativity engine, exceptional leadership, an urgent need, special team. 


\section{Smart Patterns For A Middle Eastern Knowledge City}

Five creativity engines: the Café, the Library, the Museum, the University, and the Market are selected to illustrate how urban institutions can transform into essential part of the Knowledge City network. The existence and the social, cultural and even architectural articulation of these institutions in Middle Eastern cities would facilitate the emergence of smart urban patterns which will construct the overall holistic structure of a knowledge city. However, at the end of the paper we suggest that other urban constructs might also serve as Creativity Engines.

\section{i) The Café}

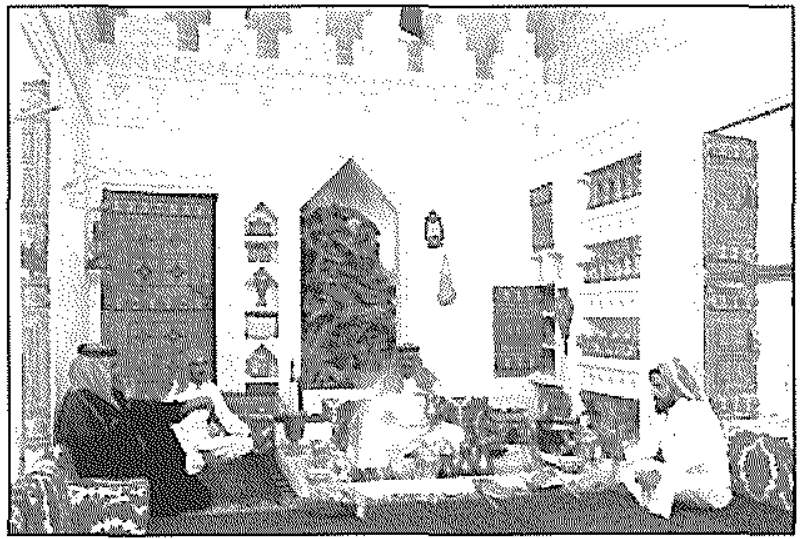

Figure 4: Traditional coffee shop (Gahwa) in Middle Eastern Cities.

The first Innovation Engine we visit is the old good Café', since knowledge and ideas are created mainly through conversations. Historically, cafés provided stimulating environment for rich conversations which led to the creation of exchange of provocative ideas and breakthrough in diverse areas such as arts, philosophy, psychology and politics. Many of the influencing ideas of the 19th Century were created at the café's of Wien and Paris, for example. It is only natural that the methodology of "Knowledge Cafe" was developed to support innovative brainstorming sessions. 


\section{ii) The library}

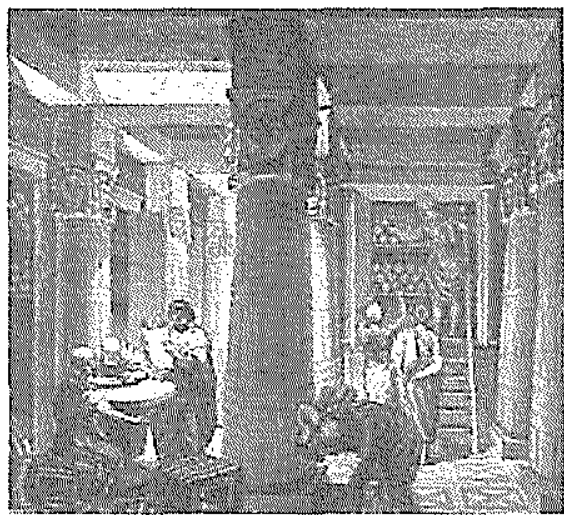

Figure 5: Scholars at the old Alexandria library

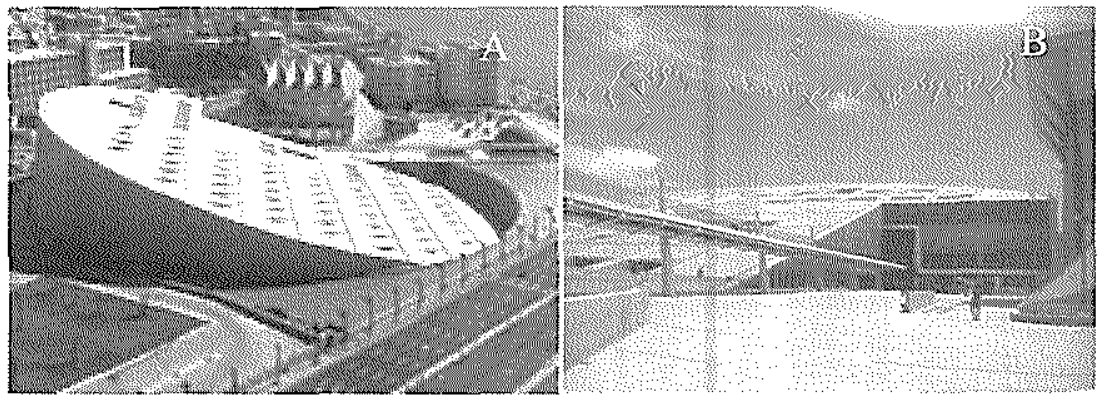

Figure 6: The New Bibliotheca Alexandrina, Egypt

Great Libraries are not only about archiving the intellectual achievements of the past generations but can serve as a place for innovation. The ancient library at Alexandria had been the western world's most important center of learning for a thousand years. The Alexandria Library was nothing less than the summit of ancient scholarship. Its archives and museum were filled with the intellectual riches of Mesopotamia, Persia, Greece, Rome and Egypt, and its research center was visited by many generations of scholars seeking to stimulate their minds and keep alive memories of the past.

Today, in an event that speaks of renewal Alexandria is trying to recapture the spirit of perhaps its richest legacy-the Great Library of Alexandria-by opening the new Bibliotheca Alexandrina. 
iii) The Museum

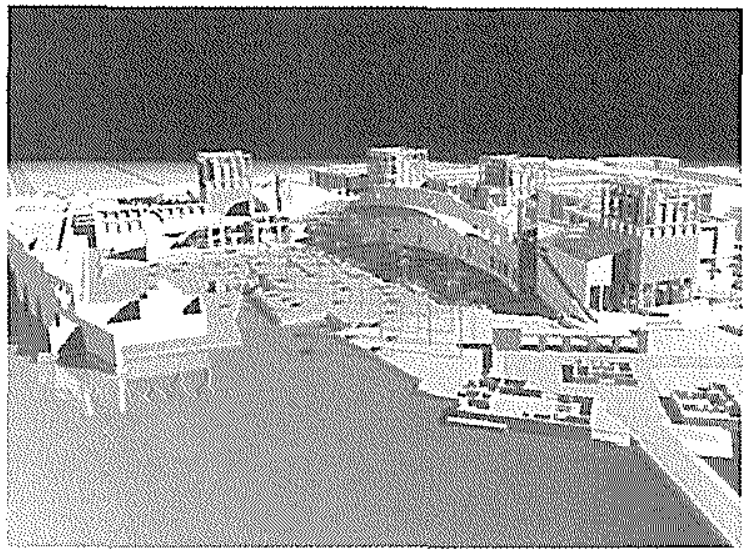

Figure 7: Islamic Museum, Qatar: A knowledge center integrated with the city.

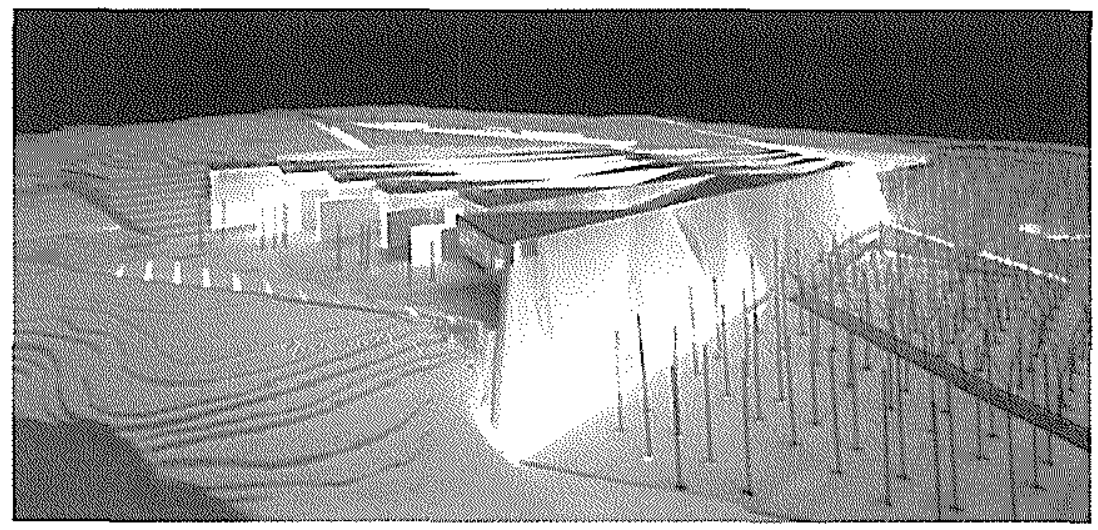

Figure 8: The New Civilization Museum., Egypt: More transparency and openness

Similarly to the case of libraries, great museums not only show past cultural achievements but can also serve as hosts and stimulators of innovation in diverse arts fields as well as in other areas.

One of the best examples is the Guggenheim museum at Bilbao which was one of the most important ingredients in the plan to redevelop the city of Bilbao and transform this old industrial town into a knowledge city. Since it opened its doors in 1997, the museum hosted not only art events but many conferences in business innovation, intellectual capital and similar domains. It was a full day visit to the museum that 
led the author to the idea that art could and should take an important role in EC funded research projects.

iv) The University

The University of California, Berkeley in San Francisco, the colleges of Oxford, MIT and Harvard at Boston, Le Sorbonne in Paris, and Monterrey Tech at Monterrey. All are fine examples of the scale, quality and different kind of innovativeness that a good university can contribute to a city. In all visions and strategic plans of knowledge cities, the local universities play an instrumental role. However, beware of ivory towers. It is not enough to nourish the academic excellence of the university. The multi-faceted linked between the university and the city citizens - children, teachers, business people, artists, industrialists, etc - turn the university from a learning and research center into an innovation engine.

\section{Endless/Timeless Creativity Engines:}

How can cities turn other urban places and institutions into engines for creativity? We believe that creative thinking based on collaborative efforts of all stakeholders - citizens, business people, policy makers, educators etc. - can lead to interesting answers. For example, what about the following constructs of the city (see figures from 9 to 15 ).

\section{FINAL RECOMMENDATIONS}

- Knowledge cities should be perceived as the opportunity for new sustainable growth and prosperity in the global knowledge-based economy.

- The emerging knowledge cities in the Middle East should be seen as a regional knowledge network. The ultimate goal is to increase the innovation and creative capacity of cities based on a new set of knowledge patterns.

- An active community of knowledge sensitive cities or regions will learn from each other. The pre-condition for participation is the willingness to share the experience with other members of this unique community. 


\begin{tabular}{|c|c|c|}
\hline $\begin{array}{l}\text { Pigure } 9: \\
\text { Figur } \\
\text { Kindergarten as An } \\
\text { Interactive Knowledge } \\
\text { based Environment. }\end{array}$ & $\begin{array}{l}\text { Figure } \\
\text { Plaza or Com }\end{array}$ & 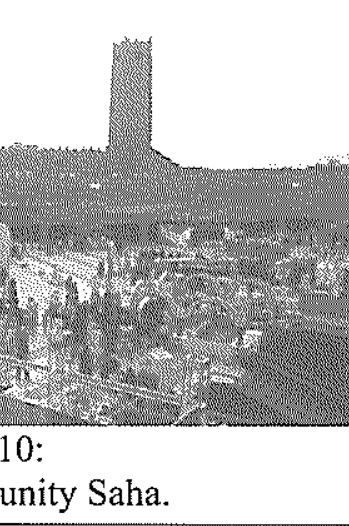 \\
\hline \begin{tabular}{|l} 
(2) \\
Figure 11: \\
Street as an Opportunity \\
for Knowledge \\
Encounters
\end{tabular} & $\begin{array}{l}\text { Figure 12: } \\
\text { Public Buildings which } \\
\text { Communicate. }\end{array}$ & 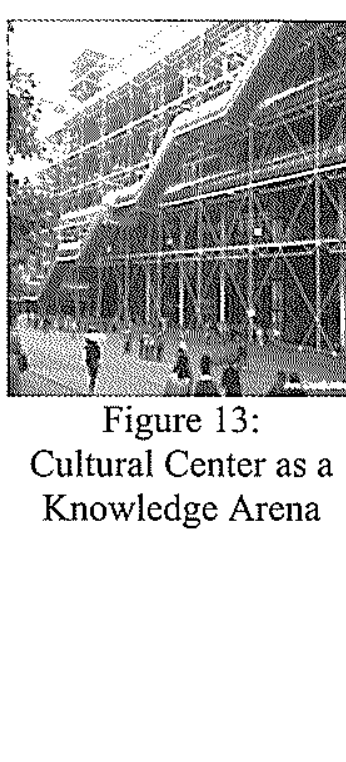 \\
\hline 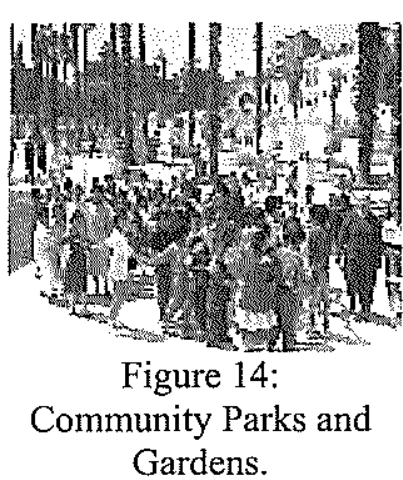 & 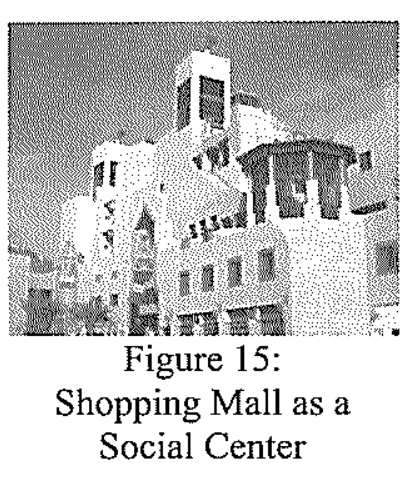 & $\begin{array}{c}\text { And...Endless/ } \\
\text { Timeless Creativity } \\
\text { Engines. }\end{array}$ \\
\hline
\end{tabular}


- The process of creating Middle Eastern knowledge cities should be shifted from focusing on creating isolated and separated knowledge centers to a process by which a knowledge network is established and shared by different sectors of the community.

- A comprehensive examination of the history of Islamic and Middle Eastern Cities is urgently needed to provide contemporary planners, urban designers and architects with tools and patterns which were used successfully to disseminate knowledge in traditional built environments.

- The making of a $\mathrm{KC}$ is a long and complicated process, but for sure it is the path to follow for the most sustainable urban development. Examples of $\mathrm{KC}$ best practices can be guidance for cities that are willing to pursue knowledge-based development. However, it should not be forgotten that each city is unique and characterised by different cultural, economic and political conditions. Therefore, $\mathrm{KC}$ strategies need to be customised to the unique urban circumstances, competencies, opportunities and challenges.

- A Knowledge City is a place where the outcomes and by-products of information technology are widely available to all. The physical configuration of the city would educate the people and even by just living in the city they would absorb the manifestations of culture. Facades, landscapes, city elements, etc. are designed and arranged in such a way to remind residents of the cultural presence. Moreover, well-equipped cultural centres evenly distributed throughout the city would be available to all without exception.

- Research is also a prerequisite of a Knowledge City. It requires infrastructure of research, an issue which has not been developed in the Middle East. Hence, an inclusive initiative to prepare the grounds for a major transformation must be translated into strategy.

- A network between Middle Eastern cities needs to be established to facilitate the following:

- Creating annual events which can perform as platforms for mutual learning between cities.

- Creating and sharing of a set of comparative indicators which enhance understanding and provide a credible mechanism for evaluating the progress of a knowledge city.

- Best practices exchange. 


\section{REFERENCES}

Abel, Chris. 2000. Architecture and Identity: Responses to Cultural and Technological Change. London:Architectural Press

Abbinnett, R. 2003. Culture and Identity. Critical theories. London:Thousand Oaks

Abel, C. 1997. Architecture and Identity. Towards a Global Eco-culture. Oxford: Oxford University Press

Barcelona City Government. 2003. Culture, The Motor of the Knowledge City: Strategic Plan of the Cultural Sector of Barcelona. Barcelona, Steering Council of the Strategic Plan of the Cultural Sector of Barcelona.

Castells, M. 1983. The City and the Grassroots, Berkeley: University of California Press.

Castells, M, (ed) 1985 "High Technology, Space and Society", Vol. 28. Urban Affairs Annual, London: Sage Publication.

Castells, Manual. 1996. The Rise of The Network Society. Oxford, Blackwell.

Castells, Manual. 1998. The Information Age. Oxford: Blackwell Publishers.

Dvir, Ron. 2003. "Innovation Engines for Knowledge Cities" in ENTOVATION

100 Round Table and the Latin American Knowledge Development Forum, Monterrey, Mexico.

Dvir, R. 2003. Innovation Engines for Knowledge Cities: Historic and Contemporary Snap Shots. Ecology

Dvir, R. and E. Pasher 2004. "Innovative Engines for Knowledge Cities: An Innovation Ecology Perspective." Journal of Knowledge Management 8(5): 16-27

Edvinsson, L. 2003. Introduction to Issues in Knowledge Management. Oxfordshire: Henley Knowledge Management Forum

Ergazakis, K., K. Metaxiotis and J. Psarras. 2004. "Towards Knowledge Cities: Conceptual Analysis and Success Stories." Journal of Knowledge Management 8(5): 5-15

El-Khoury, R. \& Robbins, E. (Eds.) 2003. Shaping the City, Studies in Urban Design, History and Theory. London: Routledge

ENTOVATION 100. 2003. Round Table and the Latin American Knowledge Development Forum, Monterrey, Mexico.

ENTOVATION 100. 2004. Roundtable, Bacelona, Spain.

Howells, R. 2003. Visual Cultur. Polito, Cambridge.

King, Anthony D. 2004. Spaces of Global Cultures, Architecture, Urbanism, Identity. London: Routledge 
Lefaivre, Liane \& Tzonis, Alexander. 2003. Architecture and Identity in a Globalized World by Architecture in Focus Series: Prestel Miles, M. \& Hall, T. (Eds.) 2003. Urban Futures. London: Routledge Morse, Suzanne. 2004. Smart Communities Jossey-Bass

Neil, William. 2003. Urban Planning and Cultural Identity. London: Routledge Sasse, Saskia. 1991. The Global City, Princeton: Princeton University Press

\section{Related Web Sites:}

http://www.melbourne.vic.gov.au/cityplan

http://www.delft.nl/kennisstad/en/

http://www.barcelona2004.org

http://www.entovation.com/

http://www.inthekzone.com/ 